\title{
A profissionalidade docente na educação básica em Portugal: depoimentos de alguns professores
}

Idevaldo da Silva Bodião

Universidade Federal do Ceará

João Formosinho

Universidade do Minho

\section{Resumo}

Este texto, que faz parte de um estudo de caso que busca compreender as dinâmicas pedagógicas do cotidiano de uma escola de $1^{\circ}$ ciclo da educação básica em Portugal, explora alguns aspectos da construção da profissionalidade docente, a partir de entrevistas semiestruturadas realizadas com quatro professoras de uma escola pública localizada na cidade de Braga. A análise dos dados, pautadas na "impregnação" e "interpretação" como propostas por Michelat (1982), foi organizada em torno de quatro categorias: a formação inicial; o início da carreira docente; o exercício da profissão; e as ações de formação. É possível concluir que (i) a função docente continua se caracterizando por uma atividade solitária com as decorrências que lhe são próprias; (ii) a inexistência de estratégias de acolhimento dos novatos, associadas às dinâmicas de lotação profissional, impõe, aos professores, inícios profissionais, por vezes, desalentadores; (iii) as ações de formação, como continuam sendo oferecidas, consolidam-se mais como agências de titulações, que permitem vantagens nas progressões funcionais, do que como vetores das alterações das práticas curriculares. Tecem-se conjecturas em torno da adequação de se ter, nas escolas, profissionais experientes, a quem caberiam as tarefas de apoio aos iniciantes e, também, da importância da implantação de processos de formação profissional docente nas próprias unidades escolares, assentados na lógica da constituição de grupos de reflexões.

\section{Palavras-chave}

Educação básica - Profissionalidade docente - Formação de professores.

Correspondência:

Idevaldo da Silva Bodião

Rua Julio Lima, 300 - casa 7

60822-500 - Fortaleza - CE

E-mail: idbodiao@uol.com.br 


\title{
The professionalism of teaching in Portugal's basic education: testimonies from teachers
}

Idevaldo da Silva Bodião

Universidade Federal do Ceará

João Formosinho

Universidade do Minho

\begin{abstract}
The present text, part of a case study that seeks to understand the pedagogical dynamics of the daily school life in the 1st cycle of basic education in Portugal, explores some of the aspects of the construction of teaching professionalism based on a series of semi-structured interviews conducted with four teachers from a public school located in the city of Braga. Data analysis, grounded in "impregnation" and "interpretation" as proposed by Michelat (1982), was organized around four categories: teacher initial education; the start of the teacher career; the exercise of the profession; and actions of teacher education. It is possible to conclude that: (i) the function of a teacher continues to be characterized by solitary activities, with the consequences to be expected; (ii) the absence of strategies to welcome new teachers, associated to the dynamics of teacher placing, imposes upon them professional beginnings that are often discouraging; (iii) actions of teacher education, as they continue to be offered, have established themselves more as certifying agencies that help functional ascent than as vectors of changes in curriculum practices. Considerations are made about the advantages of having in the schools experienced professionals with the task of giving support to new teachers, and also about the importance of putting in place processes of teacher professional education inside the schools, based on the logic of the constitution of reflection groups.
\end{abstract}

\section{Keywords}

Basic education - Teacher professionalism - Teacher education.

\section{Contact:}

Idevaldo da Silva Bodião

Rua Julio Lima, 300 - casa 7

60822-500 - Fortaleza - CE

E-mail:idbodiao@uol.com.br 
Com a Revolução dos Cravos, Portugal iniciou um novo período da sua história política e social, impulsionado pelos promissores ventos da democratização. Nesses novos rumos, procedeu-se, como era de se esperar, a reorganização dos arcabouços institucionais, o que incluiu o sistema educacional.

Ainda que numa visão bastante simplificada, é possível identificar traços dos ensaios autogestionários que impregnaram os momentos imediatamente pós-74, bem como as posteriores marcas das institucionalizações. É nesse segundo periodo que se edita a nova Lei de Bases do Sistema Educativo - Lei no 46/86, de 14 de outubro de 1986 -, documento que inicia a última reforma educativa do século $X X$ em Portugal (Catani; Oliveira, 2000).

Ferreira (2004), que identifica sua centralidade na configuração curricular, salienta que a nova lei não incorpora, praticamente, nada de novo nessa organização, constituída de ensino básico, obrigatório, que passa de seis para nove anos e ensino secundário de três anos. A proposição de uma área obrigatória, de natureza não disciplinar ${ }^{1}$, poderia, na expectativa de muitos educadores, constituir-se no elemento capaz de possibilitar a construção de uma nova concepção de escola que superasse a marcante visão metodologicamente tradicional e conteudista. Entendendo as escolas como o lócus de efetivação das políticas educacionais, Ferreira (2004) e Lima (2000), por exemplo, reclamam medidas que alterassem os formatos da organização e da gestão escolar como forma de contribuir para a consecução das mudanças propostas.

A partir de 1996, com o intuito de estimular novas práticas pedagógicas, iniciaram-se movimentos de reflexões participativas sobre os currículos dos ensinos básico e secundário, por meio do projeto "Gestão Flexível do Currículo". De adesão voluntária e implantação gradativa, conseguiu, em quatro anos, a incorporação de 184 unidades - essa prática culminou com promulgação do Decreto Lei $n^{\circ}$ 6/2001, do Ministério da Educação, propondo-a a todas as escolas públicas (Benavente, 2001). Seus postulados se assentavam na necessidade de se considerar a materialidade de cada escola, expressa mediante às suas proposições, cujos traços derivavam das organizações e dos funcionamentos próprios de cada estabelecimento, singularizados pelas condições de suas estruturas, dos seus acervos e das articulações entre seus profissionais.

No início de 2001, duas modificações foram institucionalizadas com a incorporação de três áreas não disciplinares e a flexibilização do tempo de duração de cada aula - DecretoLei 7/2001, de 18 de janeiro. Assim, passaram a integrar o currículo as áreas "Projeto", "Educação para a cidadania" e "Estudo comparado", ao mesmo tempo em que se abandonou a rigidez das aulas de 50 minutos, abrindo-se, desse modo, perspectivas relevantes para novas articulações temáticas e temporais.

As propostas de alterações na LBSE/86, encaminhadas pelo governo em 2003, mantiveram, nos casos dos ensinos básico e secundário, a matriz anterior, com pequenas alterações organizativas, cuja principal novidade foi a passagem da obrigatoriedade dos nove anos da, então, educação básica, para os doze anos dos ensinos básico e secundário.

É possivel identificar, desde os anos finais do século passado, um conjunto de medidas administrativo-organizacionais com consistências, articulações e intenções variáveis. A questão que se coloca é saber como essas proposições oficiais contribuíram para a consolidação de práticas pedagógicas que, efetivamente, pudessem atender aos direitos dos usuários do sistema público de educação.

Para tal, não bastam análises dos documentos oficiais, uma vez que, em função de dinâmicas próprias, eles são ressignificados em cada unidade escolar, o que nos permite afirmar que, quaisquer que sejam o teor, a intencionalidade e o grau de consistência das propos-

1. Referímo-nos à "Área Escola", normatizada pelo Decreto-Lei n 286 / 89, de 29/08/1989. 
tas governamentais, não há como garantir um padrão em suas implantações. Consideramos, por outro lado, que as vivências nos cotidianos escolares se constituem, como diz Rockwell (s/d), em referências impares para que se possa documentar o não documentado.

\section{A pesquisa}

Intentando compreender melhor os processos que dão as cores locais da vida das escolas, movimento essencial para que se possa pensar em modificá-las, e tendo em vista as práticas atuais da escolarização pública portuguesa, organizada temporalmente dentro da lógica dos ciclos e administrativamente em torno dos agrupamentos de escolas ${ }^{2}$, iniciou-se uma pesquisa, numa escola de $1^{\circ}$ ciclo, na cidade de Braga, acompanhando-se suas atividades entre os meses de abril e dezembro de 2007. Nesse período, fizeram-se observações contínuas em seis classes que funcionavam no período vespertino e acompanharam-se as reuniões institucionais tanto na própria escola, quanto na sede do agrupamento e também um conjunto diversificado de ações realizadas pelos alunos ${ }^{3}$. Para completar o elenco das fontes de informações, além do estudo de textos oficiais, foram realizadas entrevistas semiestruturadas com quatro professoras, cujas classes haviam sido acompanhadas ${ }^{4}$ nas observações.

Para acomodar as disponibilidades das professoras, as entrevistas foram realizadas nos horários e locais que melhor lhes aprouvessem, concentrando-se nos períodos próximos das suas atividades escolares, o que nos obrigou, sempre, a mais de um encontro.

Para a apresentação deste texto, o trabalho de análises focou os dados relativos a essas entrevistas e fez o que Michelat (1982) denomina impregnação e interpretação:

0 procedimento adotado vai consistir em ler e reler as entrevistas disponíveis para chegar a uma espécie de impregnação. [...] As leituras repetidas vão progressivamente suscitar interpretações pelo relacionamento de elementos de diversos tipos. Por interpretação compreendemos, como os psicanalistas, o 'destacamento, pela investigação analítica, do sentido latente a partir do conteúdo manifesto'. (p. 204-205)

Assim, a definição das categorias de organização dos dados foi feita por um processo de aproximações progressivas, em que os elementos explicitaram-se, mais claramente, à medida que se estabeleceram relações entre eles ou com variáveis consideradas próximas. Michelat (1982) é bastante elucidativo, ao dizer:

Após o período de impregnação pelo material, progressivamente se vai adquirindo a capacidade de elaborar um esquema provisório a partir de uma ou de muitas entrevistas. [...] Dedica-se a uma releitura das entrevistas e amplia-se, precisa-se, modifica-se o esquema inicial. À medida que se progride, os diferentes elementos integramse progressivamente no esquema. (p. 206)

Tecnicamente esse procedimento poderia, de forma teórica, não ter fim. A análise aqui apresentada pretende ter conseguido um grau aceitável de coerência interna, constituindo-se numa factível leitura do real, como ele pode ter sido vivido. Não se imagina ter composto um quadro completo da complexa problemática abordada, pretendendo-se, apenas, ter dado um sentido orgânico ao conjunto das intervenções das professoras captadas pelas entrevistas realizadas.

Ainda que não se cogite na generalização das elaborações aqui tratadas, parece plausível dizer que elas encontram razoável ressonância

2. Na organização do sistema escolar público português, as escolas de $1^{\circ}$ ciclo, as EB1, estão vinculadas, administrativamente, a escolas de $2^{\circ}$ e $3^{\circ}$ ciclos, as EB 2, 3.

3. As participações nas "Marchas de Santo Antônio", na "Braga Romana", no lançamento da Campanha da Fraternidade e na visita ao Museu da Sé são exemplos dessas atividades.

4. Alegando motivos de ordem pessoal, duas professoras não se deixaram entrevistar. 
no histórico profissional de muitos professores do mesmo período, fato que, se confirmado, ajuda a melhor compreender como as dinâmicas de algumas escolas portuguesas evoluíram para o que são atualmente.

\section{Expectativas, decepções, alegrias e tensões: histórias profissionais de professoras de $1^{\circ}$ Ciclo}

\section{A formação inicial}

As professoras mais antigas, como Camélia e $1 \mathrm{sa}^{5}$, completaram suas formações iniciais em nível secundário, em escolas técnicas, com caráter de terminalidade, ou em liceus, que permitiam o acesso aos cursos superiores. As mais novas já as fizeram em nível superior, por meio de licenciaturas nos institutos politécnicos.

Sem mostrar qualquer contrariedade por não ter feito um curso voltado para Artes Plásticas, sua opção preferencial naquele momento, Isa conta que concluíra o curso de magistério por não poder mudar-se de cidade, completando, de forma saborosamente enfática, “... e gostei!”.

Camélia, que completara o liceu, chegou a iniciar curso superior de Direito, tendo desistido ao término das primeiras disciplinas cursadas; "achei muito pobre", disse e, depois de comentar alguns dos conteúdos estudados, completou: "não me aliciou".

Tempos depois, induzidas pelas novas legislações que favoreciam os portadores de diplomas de licenciaturas, cada qual formalizou sua titulação em nível superior. Isa iniciou seu processo na Universidade do Minho, interrompendo-o por razões de ordens econômicas, completando-o, posteriormente, mediante o curso da Universidade Aberta. Sem qualquer constrangimento, reconhece que uma motivação forte fora o fato que "o acesso ao topo da carreira só é (era) dado aos licenciados”. Camélia, que havia desistido do curso de Direito, já no exercício da função docente, terminou sua licenciatura na área da Gestão Escolar.
As mais novas, Lia e Zabela, titularam-se, respectivamente, no Instituto Politécnico de Lisboa e no Instituto Politécnico de Bragança, completando suas licenciaturas, o que, naquele momento, se constituía em exigência para a habilitação ao exercício da docência em escolas do $1^{\circ}$ ciclo.

Instadas a falar sobre esses cursos, mesmo fazendo alguns reparos, reconhecem-nos como relevantes e consideram que lhes haviam dado as bases suficientes para o exercício da profissão. Ao discorrer, especificamente, sobre seus professores, tanto fazem elogios pessoais, quanto críticas contundentes.

As professoras dizem ter iniciado suas vivências no cotidiano das escolas durante seus cursos de formação inicial, por intermédio dos estágios disciplinares. Zabela, por exemplo, faz alusão explicita ao fato de tê-los feito desde o primeiro ano letivo.

Quando arguida sobre sua formação inicial, lsa faz pequenos reparos a essas atividades ao dizer: "Penso que podia ter sido melhor, sobretudo em termos da prática pedagógica; acho que foi um bocadinho lacônica [...], no chamado estágio; acho que podia ter sido mais enriquecedor". Ainda assim, reconhece que a escola lhe dera as ferramentas teóricas suficientes para encaminhar as tarefas profissionais.

Camélia foi a única a fazer alusões nominais a alguns dos seus professores, sendo capaz de identificar, nesses mestres, os atributos que a seduziram: exibiam traços não autoritários no exercício da profissão e eram capazes de entusiasmar e motivar os seus alunos. Por conta desse "espírito", leu autores como Freinet e Emile Planchard, por exemplo.

Por outro lado, Zabela não mostra percepção tão positiva dos seu professores ao dizer que “o Politécnico [...] é bom, tem condições para dar bom cursos, condições materiais; a nível de condições de professores, não tem, não acho que há professores com muita facilidade... infelizmente".

5. De modo a preservar a identidade dos envolvidos, todos os nomes utilizados são fictícios. 


\section{O início na profissão docente}

\section{Entre desconfortos, situações dramáticas e boas experiências}

Todas as entrevistadas iniciaram suas vidas laborais nos períodos seguintes ao final de suas formações. Aquelas que o fizeram ao fim do curso secundário, aos 17/18 anos de idade, iniciaram nos anos de 1974 e 75, enquanto as outras, já na segunda metade da década de 1990.

Com discursos mais drásticos ou mais amenos, todas reconhecem os desconfortos dos primeiros tempos no magistério. Zabela registra as ansiedades e tensões decorrentes das primeiras aulas, enquanto Camélia fala das dificuldades de conduzir as aulas, num única classe e ao mesmo tempo, para crianças das quatro séries do $1^{\circ}$ ciclo.

Isa que, como Camélia, iniciara-se na carreira bem jovem conta que recebeu, como primeira tarefa, a responsabilidade de conduzir uma reunião com os encarregados de educação ${ }^{6}$, na qual thes deveria explicar as reformulações organizacionais e curriculares pelas quais passava o sistema educacional português naquele início do ano letivo 1975/76. Sobre esses momentos, afirma:

Quando, nos primeiros anos, eu comecei a trabalhar, senti o tal desconforto, talvez o empurrão, que ainda a um bocado me referi, o empurrão dos mais novos para... as feras, para as funções mais difíceis e senti alguma falta de identidade com a maioria dos meus colegas. [...] Acho que os professores eram frios ao receber os colegas novos, havia um trabalho muito solitário. (Profa 1 sa)

Arguida sobre a existência de dinâmicas coletivas ou institucionais que pudessem garantir um acolhimento aos que chegavam às escolas, ela afirma:

Dinâmica conjunta da escola, não! Também, não havia reuniões regulares, não havia plani- ficações conjuntas... era mesmo um ato solitário, nessa ocasião, em termos institucionais, não é? Depois estava um pouco pelo perfil do grupo. (Profa lsa)

Depois de afirmar que, em função de afinidades pessoais, conseguira realizar algumas permutas de trabalho, lsa completa: "De uma forma geral, a ideia que me fica é que era um ato muito solitário".

Ainda que houvesse iniciado suas atividades profissionais na mesma escola onde já estudara, nos subúrbios de Lisboa, fato que lhe dava o privilégio da familiaridade com aquela ambiência social, Lia considera que o seu primeiro ano no magistério foi uma experiência dramática, chegando a colocar em dúvida seus atributos profissionais: "Foi o pior ano para mim de serviço, o primeiro foi o ano que mais chorei, foi o ano em que pensei que não tinha estofo para dar aulas”. Explica que lhe atribuíram uma turma muito complicada, na qual, segundo ela, estavam alguns daqueles considerados os piores alunos da escola. De forma poético-crítica, recorre a um ditado popular para se referir a esse procedimento: "Não se divide o mal pelas aldeias, concentra-se." Mais à frente, para responder sobre o respaldo dado pela sua formação inicial para lidar com problemas como esse, ela afirma:

Não se aprende tudo na universidade [...], mas eu não estava a espera de uma turma dessas, porque na universidade não é essa a mensagem que passa, passa a mensagem da escola inclusiva. [...] Não passa a mensagem de que há uma lista de antiguidades, que as turmas são escolhidas. E portanto, no estágio, não nos dão esse tipo de turmas. (Profa Lia)

Lia aborda, de forma direta, uma questão delicada, e ainda não devidamente equacionada

6. "Encarregados de Educação" é a forma como os pais ou os responsáveis pelos alunos são tratados nas escolas portuguesas. 
pelas administrações dos sistemas educativos: o início da atividade laboral e toda a problemática a ela relacionada. Noutro momento da entrevista, volta a se referir de forma drástica a esse período ("A pior experiência que eu tive foi essa”), para completar, dizendo: “Até o Natal, eu chorava quase todos os dias".

A despeito dos desconfortos decorrentes das dinâmicas naturais do início da profissão docente, lsa deixa transparecer certa positividade no dia a dia desses tempos, ao afirmar que "os meninos vinham contentes pra escola, comigo". Modesta, atribui à precariedade das condições de vida daquela comunidade escolar esse "encantamento" com a professora, ao dizer que "o local era pobre, ... é mais fácil gostar da professora”. Mais à frente, sintetiza as condições de vida de seus alunos com uma frase emblemática: "0 Manel tinha um guardachuvas, o restante vinha com serapilheira".

Camélia refere-se com muito gosto à sua primeira experiência, e Zabela, mais entusiasmada, admite que, depois das tensões e incertezas iniciais, adorou o seu primeiro ano profissional, dizendo terem, ela e seus alunos, brincado muito (“Eu brincava tanto, tanto, tanto, com eles”). Por conta dessa integração, fez amizades que conservava 10 anos depois. Ainda assim, aludindo às suas inseguranças, não deixa de registrá-las: "Foi assustador. Os primeiros tempos. Ficar com a turma minha, sozinha, na sala”.

\section{As piores tarefas para os iniciantes}

Arguidas sobre os inícios profissionais de outros colegas, são claras ao reafirmar algo semelhante ao que lhes acontecera: aos professores novatos, quase sempre, são designadas as piores tarefas e as turmas mais difíceis, uma vez que os mais antigos são os primeiros a fazer suas escolhas.

Isa confirma essa ideia e, pensativa, afirma: "Eu acho que se pudesse quantificar, eu acho que 50\% da vezes é um pouco esse o espírito ou mais... (enfática) ou mais!" Mais à frente, reitera:
"Ao longo desses meus 30 anos de serviço, acho que metade dos anos tive esse sentimento".

Quando fala dos critérios de escolha das classes no processo de lotação profissional, ela diz: "Era pela antiguidade na escola... e depois viria a graduação profissional, ou seja, a valorização com os anos de serviço, depois idade" (Profa lsa). Mesmo mostrando dúvidas quanto à existência de bases legais para esses procedimentos, confirma que os mais novos eram os últimos a escolher suas turmas.

Enquanto narra as dificuldades da sua experiência no início de carreira, Lia se refere às atribuições das piores turmas aos professores novatos como um fato comum e não só detalha as formatações desses procedimentos, como também assinala algumas das razões que os podem explicar ao afirmar:

É (comum)..., por isso é que, quando a senhora ministra, às vezes, diz que se deve dar a voz à experiência, aos colegas mais velhos, que já têm mais experiência, eu acho que essa voz deve ser dada junto dessas turmas. Mesmo que não fiquem com essas turmas, (devem) apoiar os colegas que ficaram com essas turmas mais complicadas, porque a experiência pode ajudar, de fato, a ultrapassar algumas questões mais difíceis. Mas, normalmente é..., porque os colegas mais velhos, que podem escolher as turmas e os horários, logicamente vão escolher as turmas que não lhes dão tanto trabalho e tanta dor de cabeça, ao longo do ano letivo, e essas turmas ficam para os colegas que vêm mais tarde, que são os mais novos, que são os últimos da lista, portanto que têm menos tempo de serviço. É essa a lógica." (Profa Lia)

Ainda que não seja simples desconsiderar a meritocracia como princípio na atribuição das aulas aos professores, critério que costuma ser combinado com número de anos de serviço e atividades especiais realizadas, o depoimento de Lia explicita, com precisão cirúrgica, os efei- 
tos dessa lógica que, ao final, resulta por impor aos mais frágeis - professores e alunos as situações mais adversas.

\section{Os papéis individuais dos colegas}

Mesmo que fossem arguidas, especificamente, sobre procedimentos institucionais de acolhimento aos novatos, nenhuma das entrevistadas foi capaz de identificá-los. Ao mesmo tempo, referiram-se às contribuições pessoais de colegas mais experientes como tendo se constituído em apoios importantes que as ajudaram a superar os desconfortos e as dificuldades do início da profissão.

Zabela ressalta o papel das colegas na sua percepção das necessárias adaptações às práticas do dia a dia, das abordagens que estudara no seu curso de licenciatura:

Eu aprendi muito com as colegas que tive, interessei-me em aprender logo no primeiro ano, em me informar com as colegas mais antigas, como funcionava, como não funcionava, como era, como não era, [...] e prontas a ajudar, prontas em tudo, acho que lá havia um companheirismo que era um coisa maravilhosa, as pessoas ajudavam-se, viam que éramos raparigas novas e davam logo conselhos, isto assim, assim, não faças assim, não faças assado. (Profa Zabela)

Lia reconhece que, para superar a sua dramática experiência inicial, foi vital a ajuda de uma particular colega, que estava às vésperas da aposentadoria. Ela diz:

Essa colega mais velha foi a única que tentou dar a mão, ela ia para a reforma. E que me ensinou. Eu perguntava-lhe coisas e ela ensinava, não era como as outras colegas [...] e chegou a oferecer-se para dar aulas, à minha sala, de Expressão Dramática, para ver se através da expressão dramática eles se portavam melhor. E ela começou a dizer: 'o problema não é teu, porque esta turma é do mais complicado que eu vi até hoje'. E era uma pessoa que tinha trinta e tal anos de serviço. (Profa Lia)

\section{O exercício da profissão docente}

\section{De professores contratados a efetivos}

0 início da carreira profissional foi, para todas, muito semelhante, pois, na condição de professoras agregadas/contratadas, tinham garantia de trabalho e de lotação numa específica escola, no máximo, durante um ano letivo, ao final do qual precisavam apresentar novas candidaturas, o que, em geral, as levavam para outros estabelecimentos. Cumpridos os rituais próprios, apresentaram-se, cada qual a seu tempo, aos concursos oficiais, pleiteando vagas como professoras efetivas, o que lhes garantia a estabilidade em dada escola, se assim lhes aprouvesse.

A trajetória de Camélia espelha essa situação, pois ainda que os encarregados de educação houvessem gostado do seu trabalho, a dinâmica oficial a obrigara a participar de outro processo seletivo, tendo mudado de escola no final do seu primeiro ano letivo. Ao longo da conversa, cita uma lista de freguesias e escolas por onde afirma ter ficado somente por um ano.

Isa narra percurso semelhante, com mudanças anuais de escolas, o que a levara a algumas escolas rurais, cujos acessos, difíceis, demandavam, às vezes, trajetos combinados com autocarros, "boleias" e percursos pedonais.

Referindo-se, de forma entusiasmada, às suas relações com os alunos e suas famílias, Zabela, semelhante às colegas, diz ter deixado a escola ao final do seu primeiro ano de trabalho, ainda que os encarregados de educação houvessem se mobilizado para que ela ficasse:

Quando eu me vim embora, eu lembro-me da mãe da minha Fátima, uma miúda problemática [...] se agarrar a mim e a agradecer por ter feito o que fiz [...] e a pedir-me 
para eu não largar a turma. [...]. Eu disse, eu não posso fazer isso, a não ser que seja colocada novamente aqui. 'Ai, mas nós vamos juntar os pais da turma, vamos juntar e vamos pedir.' [...] Eles realmente pediram, mas não podiam fazer nada, eu tinha que ir mesmo a concurso. (Profa Zabela)

Lia também mudou de escola ao final do primeiro ano e, nesse novo estabelecimento, pôde, excepcionalmente, ficar por três anos consecutivos, ainda que nunca tivesse certeza de poder continuar.

E consegui lá ficar três anos, porque pedia sempre (anualmente) na DREL, na Direção Regional de Educação de Lisboa, para ver se havia possibilidade de lá estar, e as pessoas que estavam a comandar a escola também gostaram do meu trabalho. Pedíamos para dar primazia a continuidade pedagógica e a diretora regional sempre acedeu a esse meu pedido... (Profa Lia)

Fala, a seguir, de uma série de escolas por onde passou, até que, depois de ter se apresentado para concurso na categoria de professora efetiva, pôde permanecer na atual.

lsa, que se iniciara no exercício da profissão no final da década de 1970 , ascendeu à condição de professora efetiva há mais tempo, tendo podido permanecer numa escola por 5 anos, depois mais 14 anos noutra, estando há 10 anos no mesmo estabelecimento. Camélia, que iniciou a trajetória profissional, mais ou menos, à mesma época, narra percursos semelhantes e detalha quando e como foi possível efetivar-se:

E depois os anos foram andando, entretanto eu resolvi efetivar-me, foi em 1980. (0 que era preciso?). Era um concurso à parte, era preciso ter uma determinada graduação profissional, eu penso que na altura era preciso o diploma, e depois um ponto por cada ano de serviço. Havia umas escolas que já estavam disponíveis para esse concurso. (Profa Camélia)
Em seus depoimentos, Camélia, Lia e lsa, referem-se às diferentes possibilidades profissionais e salariais a que estavam submetidos os professores efetivos e os professores agregados. Camélia vai além, traçando um paralelo com a situação que parece se desenhar com a recente instituição da figura do "professore titular" e "não titular". Aos professores efetivos e, naquele momento, aos titulares, abriam-se possibilidades profissionais e salariais que não estavam disponiveis para os professores agregados numa correspondência aos não titulares.

\section{Algumas experiências marcantes}

Ainda que se refiram às suas permanências em escolas, qualificando-as como positivas e, às vezes, utilizem adjetivos generosos, nem todas conseguem fazer alusões precisas a essas experiências.

lsa reconhece ter sido possível conseguir uma sinergia positiva em certas escolas em função da convergência de afinidades pessoais e afirma que isso permitira, aos professores que se envolveram "de alma e coração, arrastar à reboque”, como ela diz, os colegas menos envolvidos, possibilitando, assim, realizar atividades relevantes. Referindo-se a projetos específicos, diz:

Fazermos uma série de atividades, levarmos os médicos do Centro de Saúde a fazerem palestras para a população, desenvolvermos, nos espaços das festinhas da escola, temáticas ou peças de teatro ligadas à alimentação... um dos pontos. [...] Estou a me lembrar de outro ponto alto, na ocasião do Evangelho, os meninos irem fazer a representação da leitura do Evangelho. Uma aluna minha, que era cega, fazer a leitura em Braille na igreja. [...] São pontos altos, que vivenciei nessa escola. (Profa ${ }^{a}$ lsa)

Fala, também, de um aluno com deficiência mental profunda, que havia tirado bilhete de identidade e aprendera a contar dinheiro, e que, junto com os demais colegas de classe, o 
que incluía a aluna cega acima referida, devidamente acompanhados pela professora, iam a andar pela freguesia em cafés e mercearias. Ele a fazer pagamentos e conferir trocos, e ela a fazer ligações telefónicas, o que lhes permitia exercitar, de forma significativa e compartilhada, suas recentes conquistas.

Atribui o mérito dessas empreitadas às características próprias dessa particular comunidade escolar, sobretudo aos papéis desempenhados pelos pais e professores, alguns deles com um "grande enraizamento" com a comunidade, como ela o reconhece.

Referindo-se a experiências pedagógicas importantes, Zabela cita uma pesquisa realizada pelos alunos de um $4^{\circ}$ ano, com trabalhos de campo, nos quais as crianças entrevistaram alguns dos cidadãos mais velhos e algumas das autoridades locais. Ela afirma:

Achei muito bom, porque ficaram a conhecer as raizes deles [...] e assim eles ficaram a conhecer a própria ilha, por que muitos não sabem da terra onde estão, [...] muitos deles nem sequer iam à praia, os que estavam mais no campo, nem sequer conheciam a praia lá da Madeira. (Profa Zabela)

Faz referência entusiasmada ao livro, escrito por esses alunos, sobre a história de Sino Grande, uma aldeia da llha da Madeira, "que era o sítio onde estava a dar aulas".

Algumas passaram por funções que fazem parte dos organogramas dos agrupamentos, tais como coordenações de escolas ou coordenações de anos. Exerceram também funções distintas, participando de grupos como o de educação especial ou ainda na gestão de bibliotecas.

Zabela, por exemplo, esteve lotada em salas de apoio, em bibliotecas e no ensino recorrente noturno oferecido para adultos. Também fez parte do grupo gestor de uma escola, período em que ajudou a organizar o esforço local para a sua permanência em funcionamento, num momento em que a lógica oficial levaria ao fechamento.
Camélia, que também fora presidente do Conselho Executivo de uma escola, relata uma experiência de 13 anos num estabelecimento para deficientes auditivos, onde conduziu a estruturação do seu funcionamento. "Quando estava pronto, sai”, afirma. Elaborou, durante essa época, uma concepção vanguardista de “educação inclusiva”, tendo conseguido o acolhimento, em classes regulares, dos alunos egressos daquela escola.

lsa também exerceu atividades de coordenação de ano e fez parte da equipe de educação especial de um agrupamento, função que declinou por se reconhecer como uma profissional da sala de aula.

\section{Sobre competências e "trocas" profissionais}

As professoras, em boa parte das vezes, não conseguiram identificar as origens de certas competências que haviam desenvolvido. Elogiadas pela forma sensível e adequada com que haviam tratado, pedagogicamente, as evoluções dos seus alunos com necessidades edu-cativas especiais, curiosamente, lsa e Lia deram a mesma resposta, afirmando, taxativas: "Não foi na formação inicial!”. Ainda que tenham apresentado suas compreensões e os motivos dessas ações, não foram capazes de identificar os seus nascedouros.

Noutro momento, Lia constrói raciocínio relevante, ao se referir à importância das reflexões sobre as práticas diárias, ao discorrer sobre possíveis influências de autores como Dewey, Piaget e Vigotsky, por exemplo. Depois de dizer que os estudara na faculdade, completou:

Na prática as coisas acabam por ser ainda o chamado tradicional, o antigamente [...] toda a gente diz, vamos para a faculdade e só falamos daquele autor, daquele e daquele [...] depois não refletimos que na prática aquilo tem uma razão de ser [...] e aquilo que as pessoas vão falando nessas tertúlias acabam por ser importante na prática e só depois, quando nos deparamos com algum 
problema é que vamos refletir sobre essas coisas, ai vamos buscar ... (Profa Lia)

Convidada a discorrer sobre a existência, nas escolas, de espaços institucionais para estimular reflexões coletivas, ela assinala:

E partilhar, isso era importante porque há sempre um colega que fez de uma maneira, e depois podemos concretizar com exercícios práticos, não é? Como é que vamos dar a volta a essas questões? lsso é o que falta na escola, eu acho. (Profa Lia)

Zabela se refere às reuniões do Conselho de Ano, como o espaço institucional para a ocorrências de "trocas" entre professores. No entanto, ao descrevê-las, seu relato concentra-se em procedimentos administrativo-burocráticos. Por outro lado, quando se refere às dificuldades com sua nova turma, diz tê-las encaminhado a partir de auxilios pessoais de colegas, fatos que parecem evidenciar a ineficiência pedagógica do Conselho de Ano, por um lado, e a efetividade das ajudas pessoais e informais, por outro.

Os únicos exemplos, colhidos durante a pesquisa, de trocas veiculadas em dinâmicas institucionais, aconteceram durante as reuniões de planejamento do período 2007/2008, quando duas experiências foram citadas e comentadas por algumas colegas. Sem que o grupo se houvesse debruçado sobre as intenções e os ganhos pedagógicos decorrentes de uma e de outra, elas foram acolhidas, com entusiasmo, somente pela professora lsa, que propôs algumas ampliações funcionais, o que sequer foi considerado pelo colegiado.

\section{As ações de formação}

\section{Todo mundo fez, muitos ainda fazem}

As professoras entrevistadas reconheceram, como o faz Ferreira (2008), a existência de distintas ações de formação, oferecidas por instituições diferentes, algumas das quais financiadas com recursos públicos.
Lia declara ter participado de ações de formação mesmo que estas não pontuasem nas suas ascensões nos escalões profissionais. De modo semelhante, lsa diz tê-las feito, ao mesmo tempo em que afirma que no período imediatamente após a Revolução dos Cravos foram oferecidas várias possibilidades para os recémformados, e Camélia confirma ter participado de várias delas.

Lia, Isa e Camélia citam várias entidades que, ao longo do tempo, ofereceram-nas e nomeiam, de forma recorrente, a Casa do Professor, em Braga, e a Universidade do Minho, e de forma pontual, o Centro de Formação de Loures, a Associação Nacional de Professores, além de alguns sindicatos da categoria. Assinalam que muitas dessas atividades haviam sido financiadas pelo Ministério da Educação, enquanto outras foram pagas pelos próprios professores. Para casos mais recentes, identificam financiamentos com recursos oriundos da União Europeia. Zabela, por sua vez, refere-se a atividades realizadas pelo governo da llha da Madeira, onde passou parte da sua vida profissional.

Todas reconhecem a existência de um periodo a partir do qual essas atividades passaram a pontuar na evolução da carreira profissional, sendo que lsa se arrisca a identificá-lo no início dos anos 90.

Em praticamente todos os casos relatados, as escolhas das específicas atividades foram de caráter individual. Isa diz que as fazia procurando preencher lacunas que identificava na sua formação, enquanto Lia, ao mesmo tempo em que reafirma essa lógica, identifica uma particular ação de formação proposta pelo grupo gestor da sua escola, que envolvia todos os professores do estabelecimento. Zabela nomeia duas proposições oferecidas a todos os professores da escola onde estava lotada.

Do grupo acompanhado, lia foi a única a ter completado uma pós-graduação stricto sensu, obtendo, assim, titulação em nível de mestrado, uma iniciativa de cunho estritamente pessoal. 


\section{Sobre as ações de formação e seus professores}

Embora tenham participado de inúmeras atividades de formação profissional, pouco conseguiram elucidar sobre elas, fazendo referências pontuais a algumas que lhes haviam sido particularmente significativas.

Ao se referir à ação conduzida pelo Centro de Formação de Loures, Lia identifica-a como uma proposição singular, não apenas porque fora uma demanda que partira da própria escola, mas também pelo fato de ter acontecido de forma contínua e regular ao longo de mais de um ano.

Além dessa atividade, nomeia outra, voltada para o ensino de Matemática, que também se realizava de forma contínua, com encontros quinzenais e com atenções voltadas, de forma prática, para as questões das salas de aula. Diferencia-a das demais não somente pela continuidade, mas também por lhe atribuir a virtude de estimular, nos professores, reflexões sobre o cotidiano das suas aulas, o que, no seu entendimento, as demais propostas não o haviam feito.

Zabela cita duas ações de formação que considera relevantes: a primeira, obrigatória, tratava da qualificação das compreensões sobre a SIDA; enquanto a segunda, referia-se ao uso de linguagens artísticas nas abordagens das disciplinas curriculares. Refere-se à primeira com mais entusiasmo, aludindo à sua duração, dois meses, com dois encontros semanais, aos conteúdos abordados, que foram importantes para si, e aos jogos e materiais oferecidos, que foram utilizados com seus alunos.

Diferente do que parece ter acontecido nas escolas do continente, Zabela registra o fato de acompanharem essas atividades durante seus horários de trabalhos, ainda que não nos horários de suas aula e completa: "Lá facilitam muito, a esse nível, facilitam muito".

Ainda que tenha participado de inúmeras atividades de formação, lsa reconhece que aprendera, de fato, com os seus colegas, por meio das trocas que se estabeleceram nos espa- ços informais de encontros nas escolas, quase sempre alimentados por afinidades pessoais. Quando é arguida sobre a elaboração de sofisticada competência profissional demonstrada em algumas aulas, ela a atribui a construções pessoais, cogitando que as ações de formação que participara, de alguma forma, haviam contribuido. Questionada sobre quais dessas atividades teriam sido particularmente significativas, teve dificuldades em nomeá-las, conseguindo fazê-lo somente para uma influência específica, que denominou "área vocabular", identificando a atividade de formação correspondente.

Camélia foi a única a citar vários professores que a haviam influenciado, referindo-se, por exemplo, a um professor de música, que identificou nominalmente, ou ainda ao professor de uma ação de formação realizada em Zagreb, que ela, orgulhosamente, apresentou como sendo amigo de Sartre.

\section{Considerações finais}

\section{A função docente: tarefa solitária, de início delicado}

Reconhece-se, de início, que Portugal deu um grande salto formal, no último quarto do século passado, ao exigir como condição mínima para o exercício da atividade docente a titulação em nível superior, processo que tanto trouxe benefícios, quanto carregou consigo alguns dos efeitos associados às lógicas insti-tucionais e organizacionais próprias das universidades (Formosinho, 2002)

Nas intervenções das professoras entrevistadas, evidencia-se o reconhecimento de terem recebido, nas suas formações iniciais, seja em nível médio ou em nível superior, os instrumentos teóricos suficientes para o início na profissão. No entanto, percebe-se também que se depararam com a inexistência de estratégias institucionais de acolhimento aos novatos, o que, para piorar, era acompanhada de uma dinâmica perversa, própria da carreira docente nas redes públicas: os iniciantes, no geral, eram indicados para as turmas mais difícieis. 
Em estudo realizado com professores das séries iniciais do ensino fundamental, em Minas Gerais, Freitas (2002) explicita a existência do mesmo padrão de comportamentos, ao afirmar:

[...] verificamos que é comum nas escolas pesquisadas delegar ao professor iniciante as turmas consideradas mais difíceis, isto é, aquelas que possuem o maior grau de complexidade, tanto no que diz respeito às estratégias didáticas a adotar, quanto no que se refere à disciplina. (p. 160)

Ainda que não se possa esperar que as graduações deem conta de toda a problemática atinente às profissões quaisquer que sejam elas, é importante notar que há, para um conjunto de carreiras, uma diferenciação clara entre as tarefas atribuídas aos iniciantes e aquelas que devem ficar sob responsabilidade dos mais experientes. A inexistência de qualquer estratégia de iniciação profissional nas escolas públicas (Bodião, 2007) faz com que o choque de realidade possa chegar a extremos dramáticos, como no caso relatado pela professora lia ao assumir a sua primeira classe em Loures.

Mesmo que tantos, como ela, tenham conseguido superar essas experiências, há de se perguntar o quanto essas vivências terão custado para os envolvidos e, principalmente, quais teriam sido os ganhos, para ambos, se tais questões tivessem, ao seu tempo, encaminhamentos institucionais distintos.

Como a generalização desses procedimentos deve ser maior do que gostaríamos, defendemos o teor da ideia proposta por lia em sua entrevista, a de ações conjugadas entre os novatos e os professores mais experientes, como ponto de partida para um novo equacionamento dessa questão. Nesse caso, atribuirse-iam, a estes, responsabilidades explícitas no partilhamento das gestões pedagógicas das classes "mais difíceis", tipificando-as profissionalmente, com os reconhecimentos dos direitos trabalhistas próprios dessa caracterização. Objetiva-se, dessa forma, garantir um acompanha- mento aos professores novos nos seus primeiros anos de profissão.

Tratando de percepções e possibilidades distintas de profissionais experientes e novatos, Alarcão (1996) apresenta elementos relevantes dessa relação:

0 que a mim me parece poder ser muito interessante na relação entre um formando e um profissional é a relação catalizadora que se pode estabelecer entre estes momentos e formas de conhecimento. As questionações do formando podem constituir um desafio para o aprofundamento e a consciencialização do saber do profissional ao mesmo tempo em que os conhecimento do formando, se atualizados, podem ser uma fonte de alimentação contínua do formador. (p. 32)

Se considerarmos a figura do formando semelhante a do recém-formado, explicita-se, nessa proposição, uma agumentação importante, uma vez que ressalta, como possíveis, trocas em que se densificam as concepções e vivências tanto dos noviços, como dos professores experientes. Ou seja, para além do apoio aos iniciantes, os professores-tutores também elaborarão novas percepções.

Outra característica do início da profissão, evidente nas intervenções das professoras entrevistadas, é sua alta rotatividade, fato que as obrigou a afastamentos das escolas ao fim de breves períodos de inserções. Se considerarmos que a atividade educacional deve ser, essencialmente, uma ação coletiva, evidenciam, de imediato, os prejuizos dessas transferências, alguns dos quais presentes nos próprios depoimentos.

$\mathrm{Na}$ qualidade de elo mais frágil na correlação de forças que se instala em cada uma das escolas, tem cabido aos professores com vínculos trabalhistas mais frágeis, as tarefas mais difíceis e as turmas mais problemáticas. Ainda que não se deva esperar a eliminação desses profissionais, uma vez que uma rede escolar precisa de professores para o prenchimento de lacunas temporais, é importante definirem-se 
diretrizes que minimizem o número daqueles nesse enquadramento funcional.

0 processo de implantação da escolarização "a tempo inteiro”, como estavam a ser vivenciados durante a pesquisa, parecia, no entanto, caminhar em sentido oposto, uma vez que criavam novos estamentos profissionais para enquadrar os professores que atuavam fora do período entre 9 horas e $15 \mathrm{~h} 30$ e que deveriam ser contratados pelas autarquias municipais. Tal problema se agravava ao serem considerados os profissionais que passaram a trabalhar nos horários anteriores às 9 horas ou posteriores às $17 \mathrm{~h} 30$ que, contratados pelas juntas de freguesias, eram pagos com recursos das familias.

A se estabilizarem esses funcionamentos, passaremos a ter três grupos profissionais atuando nas escolas públicas: aqueles contratados pelo Ministério da Educação, os contratados pelas autarquias municipais e os profissionais vinculados às juntas de freguesias. Tal diversificação e suas assimetrias laborais devem gerar importantes repercussões nas dinâmicas cur-riculares, que não serão resolvidos com as práticas de incorporações de alguns desses profissionais aos colegiados institucionais dos agrupamentos de escolas.

Os vários depoimentos reafirmaram também que o exercício da função docente já era, desde os anos 1970, reconhecido como "um ato muito solitário" e que, para responder às demandas do dia a dia, cada qual teve que construir redes de solidariedades que se estabeleceram em função de afinidades pessoais, o que mostra não haver se consolidado qualquer estratégia institucional que tenha conseguido efetivar grupos de apoios entre professores, como propõem, por exemplo, Parrilla e Daniels (2004).

\section{As ações de formação e as práticas pedagógicas}

Todas as professoras entrevistadas participaram de inúmeras ações de formação, desde a época em que não lhes representavam quaisquer ganhos financeiros, o que nos permite cogitar que o faziam porque reconheciam fragilidades nas suas formações e acreditavam que esses cursos seriam capazes de ajudá-las nessas superações. É importante reconhecer que o processo de reconstrução institucional e identitário, depois da Revolução dos Cravos, criou uma ambiência de entusiasmo em que muitos se sentiram sujeitos importantes dessas elaborações, fator que estimulou os professores a envolvimentos mais efetivos com sua profissão.

Tendo sido oferecidas por várias entidades e com temáticas distintas, essas ações de formação tiveram, no geral, formatos semelhantes: foram cursos de curta duração, marcadamente acadêmicos, oferecidos fora dos espaços das escolas, boa parte das vezes entre finais e inícios de anos letivos e escolhidos pelos professores, segundo critérios pessoais. Os casos excepcionais, como a proposta conduzida pelo Centro de Formação de Loures e as atividades de Matemática, oferecidas pela Universidade do Minho, são exceções que confirmam a regra.

Referindo-se ao forte incremento quantitativo de ações de formação das décadas de 80 e 90 do século passado, Ferreira (2008) afirma que "esse incremento não teve equivalente na transformação das concepções e práticas de formação...”. Mais à frente, completa:

\section{[...] a formação contínua desenvolveu-se predominantemente à imagem do modelo formal de escolarização e com influências de lógicas de racionalização das reformas educativas. (p. 240)}

0 fato de as professoras não discorrerem mais detalhadamente sobre quase nenhum desses cursos, somado ao de não identificarem nas suas competências profissionais possíveis influências dessas ações, ajudam a sedimentar a ideia de que essas ações de formação não parecem ter se constituido nos movimentos

7. Pimenta (2002) pontua, como marcantes, a publicação e difusão do livro "Os professores e sua formação", coordenado pelo professor António Nóvoa e a realização do I Congresso sobre Formação de Professores nos Países de Língua e Expressão Portuguesas, realizado em Aveiro, em 1993. 
mais adequado para a implantação de mudanças nas práticas pedagógicas.

A específica ponderação de lsa, de que aprendera nas trocas entre os colegas das escolas, reiterada, ainda que indiretamente, por outros depoimentos, parece apontar para o mesmo sentido de elaborações apresentadas em publicações que, principalmente a partir dos anos 1990, tanto em Portugal como no Brasil $^{7}$, alimentaram as discussões em torno de conceituações como a do bricoleur, de Perrenoud (1993), ou dos professores como profissionais reflexivos, de Schön (1992) e Zeichner (1992a), por exemplo.

Tais considerações não acreditam que os professores possam, ao final de alguns desses cursos, reproduzir, em suas salas de aula, as abordagens, tal qual lhes fora proposto. Compreendem que a atividade docente, pela natureza do processo pedagógico, envolve relações entre professores e alunos e tem, por isso mesmo, uma forte dose de imprevisibilidade, o que torna impossivel para o professor a definição prévia de seus movimentos, obrigando-o a tomar (novas) decisões quase ao mesmo tempo em que se conclui o fato que gera essa necessidade.

Essa imprevisibilidade não deve, no entanto, ser usada como argumento a justificar que as decisões decorram de impulsos espontâneos que, espasmodicamente, emerjam em momentos de mágicas inspirações. Ainda que as demandas exijam respostas quase imediatas, as decisões precisam ser pautadas por processos reflexivos, presididos por um conjunto de princípios éticos e parâmetros educacionais razoavelmente bem definidos. Esses elementos, importantes para garantir as vinculações entre os gestos específicos e as intenções que os geram, são construidos ao longo da própria trajetória profissional-pessoal de cada professor, fruto de suas experiências, crenças e atitudes individuais, elementos que retroalimentam um saber fazer processual, excencialmente prático.
Pimenta (2002), referenciando-se em Zeichner (1992b), amplia a concepção de professor reflexivo, introduzindo a dimensão social presente nesses processos, propondo a consolidação das comuidades de aprendizagens, espaços institucionais, onde os professores se apoiem e se estimulem mutuamente, considerando:

[...] a) (que) a prática reflexiva deve centrar-se tanto no exercício profissional dos professores por eles mesmos, quanto nas condições sociais em que esta ocorre; b) o reconhecimento pelos professores de que seus atos são fundamentalmente políticos e que, portanto, podem se direcionar a objetivos democráticos emancipatórios; (p. 26)

Apoiada em Giroux (1990), propõem-nos um salto conceitual ao apresentar a figura do professor como um intelectual crítico/transformador e, ao fazê-lo, permite-nos reafirmar a rejeição a ideia da docência como atividade burocrática, ao mesmo tempo em que nos alerta para a necessidade de incorporar não somente as dimensões pessoais envolvidas no processo, como também aquelas de ordens sociais. Reafirma também a compreensão do processo educativo como um gesto essencialmente político, o que fortalece a visão da escola como unidade de planejamento, gestão e efetivação das políticas educacionais.

É verdade que a adesão a processos de formação profissionais assentados na lógica dos "professores reflexivos", das "comunidades de aprendizagens" ou dos "intelectuais transformadores" implicaria em assumirmos uma nova, e nada simples, cadeia de providências e organizações. No entanto, esse fato não pode justificar que os gestores, tanto no Brasil como em Portugal, continuem a replicar dinâmicas operacionais conhecidas, sobre as quais temos razoável domínio e familiaridade, mas que continuam a se mostrar incapazes de efetivar mudanças das práticas curriculares nas escolas públicas. 


\section{Referências bibliográficas}

ALARCÃO, I. Reflexão crítica sobre o pensamento de D. Schön e os programas de formação de professores. Revista da Faculdade de Educação, São Paulo, v. 22, n. 2, p. 11-42, jul/dez. 1996.

BENAVENTE, A. Portugal, 1995/2001: reflexões sobre democratização e qualidade na educação básica. Revista Ibero-Americana de Educación, n. 27, set./dez. 2001, p. 99-123.

BODIÃO, I. da S. As necessárias articulações entre as instituições de ensino superior e as secretarias de educação, na formulação e efetivação de políticas de formação profissional. In: SALES, J. Á. M. de (Org.). Formação e práticas docentes. Fortaleza: Edições ÜECE, 2007, p. 41-51.

CATANI, A. M.; OLIVEIRA, R. P. Reformas educacionais em Portugal e no Brasil. Belo Horizonte: Autêntica; 2000.

FERREIRA, F. I. Reformas educativas, formação e subjetividade dos professores. Revista Brasileira de Educação, Rio de Janeiro, v. 13, n. 38, p. 239-251, maio/ago. 2008.

FERREIRA, J. B. Políticas de continuidade e mudança na organização do ensino em Portugal: da ultima reforma educativa do século XX à primeira do século XXI. In: II COLÓQUIO LUSO-BRASILEIRO SOBRE QUESTÕES CURRICULARES. Atas... Rio de Janeiro: UERJ, 2004, p. 3814-3828.

FORMOSINHO, J. A universidade e a formação dos educadores de infância: potencialidades e dilemas. In: MACHADO, L. A. (Org.). Encontros e desencontros em educação infantil. São Paulo: Cortez, 2002, p.169-188.

FREITAS, M. N. de C. Organização escolar e socialização profissional de professores iniciantes. Cadernos de Pesquisa, n. 115, p. 155-172, mar. 2002.

GIROUX, H. Los professores como intelectuales: hacia uma pedagogia crítica del aprendizaje. Barcelona-Madri: Paidós; MEC, 1990.

LIMA, L. C. Administração escolar em Portugal: da revolução, da reforma e das decisões políticas pós-reformistas. In: CATANI, A. M.; OLIVEIRA, R. P. Reformas Educacionais em Portugal e no Brasil. Belo Horizonte: Autêntica, 2000, p. 41-76.

MICHELAT, G. Sobre a utilização da entrevista não diretiva em Sociologia. In: THIOLLENT, M. Crítica metodológica, investigação social e enquete operária. São Paulo: Pólis, 1982, p. 194-212.

PARRILLA, A.; DANIELS, H. Criação e desenvolvimento de grupos de apoio entre professores. São Paulo: Loyola, 2004.

PERRENOUD, P. Práticas pedagógicas, profissão docente e formação: perspectivas sociológicas. Lisboa: Dom Quixote, 1993.

PIMENTA, S. G. Professor reflexivo: construindo uma crítica. In: PIMENTA, S. G.; GHEDIN, E. (Orgs.). Professor reflexivo no Brasil: gênese e crítica de um conceito. São Paulo: Cortez, 2002, p. 17-52.

ROCKWELL, E. Reflexiones sobre el processo etnográfico (1982-1985). [s.l.], [s.d.], 57 p. (Mimeografado)

SCHÖN, D. A. Formar professores como profissionais reflexivos. In: NÓVOA, A. (Org.). Os professores e sua formação. Lisboa: Dom Quixote, 1992, p. 77-92.

ZEICHNER, K. Novos caminhos para o 'praticum': uma perspectiva para os anos 90. In: NÓVOA, A. (Org.). Os professores e sua formação. Lisboa: Dom Quixote, 1992a, p. 115-138.

El maestro como profissional reflexivo. Cuadernos de Pedagogía, n. 220, p. 44-49, 1992b.

Recebido em 28.06.09

Aprovado em 09.02.10

Idevaldo da Silva Bodião é professor da Faculdade de Educação da Universidade Federal do Ceará e ex-Secretário de Educação e Assistência Social de Fortaleza.

João Formosinho é professor e, atualmente, Diretor do Departamento de Ciências da Educação da Criança, do Instituto de Estudos da Criança, da Universidade do Minho. E-mail: formosinho@bragatel.pt. 